\title{
Association Between Baseline Natriuretic Peptides and Atrial Fibrillation Recurrence After Catheter Ablation
}

\author{
A Meta-Analysis \\ Yunhe Zhang, ${ }^{1}$ MD, Ao Chen, ${ }^{1}$ MD, Lei Song, ${ }^{1} \mathrm{MD}, \mathrm{Min} \mathrm{LI},{ }^{1} \mathrm{MD}$, \\ Yingmin CHEN, ${ }^{1} \mathrm{MD}$, and Ben HE, ${ }^{1} \mathrm{MD}$
}

\begin{abstract}
SUMMARY
Natriuretic peptides like B-type natriuretic peptide (BNP) and N-terminal pro-BNP (NT-pro BNP) are reported to be increased in atrial fibrillation (AF) patients. However, the prognostic roles of BNP and NT-pro BNP in post-ablation AF recurrence remain inconclusive. We performed this meta-analysis to investigate the potential role of baseline natriuretic peptides in predicting $\mathrm{AF}$ recurrence after catheter ablation.

Electronic databases were searched for studies that evaluated the potential relationship between AF recurrence and baseline BNP or NT-pro BNP levels. The pooled standardized mean difference (SMD) and 95\% confidence interval (CI) were calculated to quantify differences in BNP or NT-pro BNP levels between patients with and without AF recurrence.

Ten studies on BNP and 8 studies on NT-pro BNP were included, in which 411 of 1300 patients and 256 of 846 patients experienced AF recurrence, respectively. Overall, the pooled SMD of studies on BNP was 0.55 (95\% CI: 0.26$0.84, P<0.001)$ while the pooled SMD of studies on NT-pro BNP was 0.96 (95\% CI: $0.62-1.30, P<0.0001)$. Meta-regression was conducted by AF type, AF duration, follow-up period, left atrial dimension (LAD), and concomitant heart failure, after which subgroup analysis demonstrated only follow-up period ( 3 months or $>3$ months) in the NT-pro BNP group might account for the heterogeneity. Sensitivity analyses indicated both the results were stable.

Meta-analysis of current eligible studies suggested that both increased baseline BNP and NT-pro BNP levels are associated with greater risk of $\mathrm{AF}$ recurrence after catheter ablation, which could be biomarkers for predicting AF recurrence. (Int Heart J 2016; 57: 183-189)
\end{abstract}

Key words: BNP, NT-pro BNP, Predictive

$\mathrm{A}$ trial fibrillation (AF) is the most common arrhythmia and a rising global burden with progressive increases in prevalence, incidence, and AF-associated mortality during past decades. ${ }^{1)}$ Catheter ablation for rhythm control was recommended in specific patient populations with paroxysmal, persistent, or long-standing persistent AF by the latest guideline. ${ }^{2)}$ However, relapse is still common since the singleprocedure efficacy of AF ablation was estimated to be $60-80 \%$ in paroxysmal $\mathrm{AF}$ and $50-70 \%$ in persistent $\mathrm{AF}^{3)}$ Since ablation techniques have been developed over time, the relapse rate might be partially due to the complicated pathological mechanisms and our limited knowledge of AF. Thus, stratification of patients who will sustain a better rhythm outcome after catheter ablation may be beneficial to clinical practice.

Natriuretic peptides (BNP, NT-pro BNP) are primarily secreted by myocytes in response to a number of stimuli, and have been widely used as important diagnostic and monitoring tools for cardiovascular diseases. ${ }^{4)}$ Meanwhile, it has been shown that AF patients had higher plasma natriuretic peptide concentrations than controls and the elevated natriuretic pep- tide levels decreased when sinus rhythm was restored by transcatheter ablation. ${ }^{5-7)}$ Somehow, it is inconsistent whether increased natriuretic peptides are real predictors of $\mathrm{AF}$ recurrence or mere dysfunction of atrial rhythm and ventricular rate at certain time points. ${ }^{8)}$ Consequently, we conducted this metaanalysis that aimed to identify the association between baseline BNP or NT-pro BNP levels and AF recurrence after catheter ablation.

\section{MeTHODS}

Search Strategy and Selection Criteria: This meta-analysis was performed according to the Meta-analysis of Observational Studies in Epidemiology (MOOSE) guidelines. ${ }^{9)}$ Pubmed, Embase, Cochrane Central Register of Controlled Trials, and the ISI Web of Science were searched by two independent investigators (Y.H. Zhang and A. Chen) for English literature published up to September 1, 2015. The search items were "Natriuretic peptides", "BNP", "B-type natriuretic peptide",

From the ${ }^{1}$ Department of Cardiology, Ren Ji Hospital, School of Medicine, Shanghai Jiao Tong University, Shanghai, China.

Address for correspondence: Yingmin Chen, MD, Department of Cardiology, Ren Ji Hospital, School of Medicine, Shanghai Jiao Tong University, NO. 1630 Dongfang Road, Shanghai 200127, China. E-mail: 13681980901@139.com

Received for publication September 8, 2015. Revised and accepted October 30, 2015.

Released in advance online on J-STAGE March 11, 2016.

All rights reserved by the International Heart Journal Association. 
"brain natriuretic peptide", "NT-pro BNP", "N-terminal proBNP", "atrial fibrillation", "catheter ablation", "radiofrequency ablation", "pulmonary vein isolation", and "circumferential pulmonary vein ablation". Reference lists of retrieved articles and relevant reviews were also screened to identify potential eligible studies. Disagreements were resolved by consensus.

The inclusion criteria were: 1) catheter ablation was performed for rhythm control in AF patients; 2) follow-up period was $\geq 3$ months; and 3) baseline natriuretic peptide concentrations and AF recurrence rates were published. Studies were excluded as follows: 1) AF patients underwent rate control strategies or surgical ablation; and 2) sufficient data were not available and could not be acquired from corresponding authors.

Definitions: The classification of AF in included studies was described as paroxysmal AF (AF that terminates spontaneously or with intervention within 7 days of onset), persistent AF (continuous AF that is sustained $>7$ days), and longstanding persistent $\mathrm{AF}$ (continuous $\mathrm{AF}$ of $>12$ months duration) in terms of the duration of episodes.

The definitions of AF recurrence and freedom from AF recurrence after catheter ablation were accorded with authors' descriptions. Generally, after a post-ablation blanking period of 1-3 months, any atrial tachyarrhythmia or AF lasting $>30$ seconds recorded by ECG or 24-hour Holter monitoring during the follow-up period was defined as AF recurrence. Accordingly, the other patients sustained in sinus rhythm or without detectable atrial arrhythmias were defined as nonrecurrence patients.

Data extraction and quality assessment: The first author's name, publication year, main characteristics of the patients, AF type, AF duration, rhythm during blood sampling, left atrial dimension (LAD), baseline BNP or NT-pro BNP levels, ablation strategies, and rhythm outcome during the follow-up were extracted by two authors (Y.H. Zhang and L. Song) independently. If a study evaluated AF recurrence at different time points, we extracted the latest data. Corresponding authors were contacted by email for the missing data we needed in this metaanalysis.

For studies in which natriuretic peptide concentrations were expressed as medians and quartiles, we transformed these data into the mean and standard deviation (SD) as documented in the Cochrane Handbook. ${ }^{10)}$ Briefly, the mean was assumed to be very similar to the median, and was used directly in metaanalysis. The interquartile range width was approximately 1.35 SD and SDs were transformed in this way.

The Newcastle-Ottawa Scale (NOS) with a maximum score of 9 was used to assess the quality of eligible non-randomized studies based on the components of Selection (0-4 points), Comparability (0-2 points), and Exposure or Outcome (0-3 points). ${ }^{11)}$ In general, a higher score indicates a better methodological quality. Additionally, consensuses were reached by authors during the discussion to resolve disagreements.

Statistical analysis: The standardized mean difference (SMD) and $95 \%$ confidence interval (CI) were used to assess the continuous data in our meta-analysis, as the detection methods and units of natriuretic peptide concentrations were varied. Meanwhile, a random-effects model was used for the relatively small sample size and potential clinical heterogeneity between studies. The significance of the pooled SMD was determined by the $z$-test with a $P<0.05$ being considered as statistically significant. Statistical heterogeneity was assessed using the $I^{2}$ statistic and $I^{2} \geq 50 \%$ was considered as a sign of significant heterogeneity between studies. Meta-regression and subgroup analyses were conducted to explore the potential source of heterogeneity. For potential publication bias we performed the Begg-adjusted rank correlation test. Statistical analyses were performed with Review Manager 5.3 (The Nordic Cochrane Centre, The Cochrane Collaboration, Copenhagen, Denmark) and Stata 12.0 (StataCorp, College Station, TX, USA).

\section{RESULTS}

Study selection: A total of 430 records were retrieved after a primary search, which were further evaluated according to the identification process shown in Figure 1. The remaining 289 studies were screened by titles and abstracts after duplicates were excluded, of which 42 potential eligible full-text articles were reviewed in detail. Finally, 18 studies that met the inclusion criteria were included in our meta-analysis. Among them, 10 studies $^{8,12-20)}$ evaluated the association between baseline BNP levels and AF recurrence after catheter ablation while the 8 other studies ${ }^{21-28)}$ investigated the potential role of NT-pro BNP.

Study characteristics: The demographic and clinical properties of eligible studies are presented in Table I and Table II, respectively. Circumferential or segmental pulmonary vein isolation (PVI) was performed in all patients, whereas additional linear ablation or complex fractionated atrial electrogram (CFAE) ablation was carried out for patients who remained in AF or sustained AF was inducible after initial PVI. In the studies on BNP, 411 of 1300 patients had AF recurrence during a mean follow-up period that ranged from 3 to 33.8 months. Meanwhile, after a mean follow-up time of 3 to 13.7 months, 256 of 846 patients had experienced recurrent AF in studies on NT-pro BNP. For quality assessment, all included studies were of relatively high quality with the NOS scores ranging from 6 to 8 points. Publication bias was assessed by the Begg-adjusted rank correlation test, which demonstrated no significant publication bias existed $(P>0.05)$. As we included a small number of studies for each group, formal assessment of publication

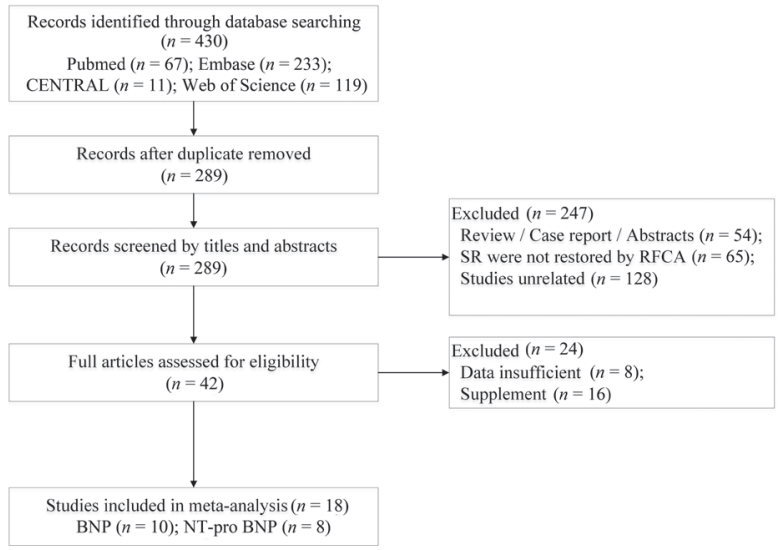

Figure 1. Flow diagram of the identification of eligible studies. SR indicates sinus rhythm and RFCA, radiofrequency catheter ablation. 
Table I. Characteristics of Studies on BNP

\begin{tabular}{|c|c|c|c|c|c|c|c|c|c|c|c|c|c|}
\hline $\begin{array}{l}\text { Author } \\
\text { (Year) }\end{array}$ & Design & $\begin{array}{c}\text { Patients } \\
\text { (Recurrence) }\end{array}$ & $\begin{array}{l}\text { Male } \\
(\%)\end{array}$ & $\begin{array}{l}\text { Age } \\
\text { (years) }\end{array}$ & $\begin{array}{c}\text { Paroxysmal } \\
\mathrm{AF}(\%)\end{array}$ & $\begin{array}{l}\text { AF Duration } \\
\text { (years) }\end{array}$ & $\begin{array}{c}\text { Concomitant } \\
\mathrm{HF}(\%)\end{array}$ & $\begin{array}{c}\text { Ablation } \\
\text { procedure }\end{array}$ & $\begin{array}{c}\text { Follow-up } \\
\text { (months) }\end{array}$ & $\begin{array}{l}\text { Rhythm } \\
\text { during blood } \\
\text { sampling }\end{array}$ & $\begin{array}{c}\mathrm{HR} \\
(\mathrm{bpm})\end{array}$ & $\begin{array}{l}\text { LAD } \\
(\mathrm{mm})\end{array}$ & NOS \\
\hline $\begin{array}{l}\text { Date, et al } \\
(2006)\end{array}$ & Retro & $53(21)$ & 47 (89) & $53.1 \pm 10.0$ & $53(100)$ & $5.2 \pm 4.6$ & None & PVI & 14 & $\begin{array}{l}33 \mathrm{SR} \text { and } \\
20 \mathrm{AF}\end{array}$ & NA & $38.2 \pm 4.9$ & 8 \\
\hline $\begin{array}{l}\text { Yamada, et al } \\
(2006)\end{array}$ & Retro & $66(31)$ & $54(82)$ & $61 \pm 10$ & $66(100)$ & $4 \pm 3$ & None & PVI & $>3$ & NA & NA & $35 \pm 5$ & 7 \\
\hline $\begin{array}{l}\text { Nakazawa, et al } \\
\text { (2009) }\end{array}$ & Pro & $51(24)$ & $45(88)$ & $58.1 \pm 10.6$ & $39(76)$ & $4.9 \pm 6.1$ & None & PVI & 6 & $\begin{array}{l}\text { most cases } \\
\text { in SR }\end{array}$ & $72 \pm 16$ & $40 \pm 4$ & 7 \\
\hline $\begin{array}{l}\text { Degener, et al } \\
\text { (2011) }\end{array}$ & Pro & 73 (19) & $56(77)$ & $53 \pm 13$ & $45(62)$ & $2.7 \pm 2.2$ & None & PVI & 3 & NA & NA & NA & 8 \\
\hline $\begin{array}{l}\text { Machino-Ohtsuka, } \\
\text { et al (2011) }\end{array}$ & Retro & $155(45)$ & $123(79)$ & $61 \pm 9$ & $100(65)$ & $5.4 \pm 4.9$ & None & PVI & $33.8 \pm 12.2$ & NA & $63 \pm 12$ & $38 \pm 6$ & 7 \\
\hline $\begin{array}{l}\text { Naruse, et al } \\
\text { (2011) }\end{array}$ & Retro & 221 (87) & $179(81)$ & $59 \pm 11$ & 127 (57) & $5.8 \pm 5.4$ & $22(10)$ & $\begin{array}{c}\text { PVI } \\
\text { PVI+LA }\end{array}$ & $31.9 \pm 7.6$ & NA & NA & NA & 7 \\
\hline $\begin{array}{l}\text { Okumura, et al } \\
\text { (2011) }\end{array}$ & Pro & $50(21)$ & $38(76)$ & $61.3 \pm 9.4$ & $28(56)$ & $5.9 \pm 6.0$ & $3(6)$ & $\begin{array}{c}\text { PVI } \\
\text { PVI+CFAE }\end{array}$ & $14.0 \pm 16.2$ & NA & NA & NA & 6 \\
\hline $\begin{array}{l}\text { Im, et al } \\
(2013)\end{array}$ & Pro & 499 (122) & 367 (74) & $56.4 \pm 11.3$ & $266(53)$ & NA & $62(12)$ & RFCA & $25.2 \pm 14.5$ & NA & NA & $41.9 \pm 6.8$ & 6 \\
\hline $\begin{array}{l}\text { Kimura, et al } \\
\text { (2014) }\end{array}$ & Pro & $44(15)$ & $38(86)$ & $59 \pm 8$ & $31(70)$ & NA & $7(16)$ & $\begin{array}{c}\text { PVI } \\
\text { PVI+CFAE }\end{array}$ & $9.7 \pm 2.4$ & NA & NA & $39 \pm 6$ & 7 \\
\hline $\begin{array}{l}\text { Pillarisetti, et al } \\
\text { (2014) }\end{array}$ & Pro & $88(26)$ & $60(68)$ & $60 \pm 8$ & $29(33)$ & NA & None & $\begin{array}{c}\text { PVI } \\
\text { PVI+CFAE }\end{array}$ & 12 & $\begin{array}{l}48 \mathrm{SR} \text { and } \\
40 \mathrm{AF}\end{array}$ & NA & $41.6 \pm 9.8$ & 8 \\
\hline
\end{tabular}

Retro indicates retrospective; Pro, prospective; AF, atrial fibrillation; SR, sinus rhythm; HF, heart failure; PVI, pulmonary vein isolation; LA, linear ablation; CFAE, complex fractionated atrial electrogram; RFCA, radiofrequency catheter ablation; LAD, left atrial dimension; NOS, Newcastle-Ottawa Scale; NA, not applicable; and HR, heart rate. Values are mean $\pm \mathrm{SD}$ or $n(\%)$.

Table II. Characteristics of Studies on NT-pro BNP

\begin{tabular}{|c|c|c|c|c|c|c|c|c|c|c|c|c|c|}
\hline $\begin{array}{l}\text { Author } \\
\text { (year) }\end{array}$ & Design & $\begin{array}{c}\text { Patients } \\
\text { (recurrence) }\end{array}$ & $\begin{array}{l}\text { Male } \\
(\%)\end{array}$ & $\begin{array}{c}\text { Age } \\
\text { (years) }\end{array}$ & $\begin{array}{c}\text { Paroxysmal } \\
\text { AF }(\%)\end{array}$ & $\begin{array}{l}\text { AF Duration } \\
\text { (years) }\end{array}$ & $\begin{array}{c}\text { Concomitant } \\
\mathrm{HF}(\%)\end{array}$ & $\begin{array}{l}\text { Ablation } \\
\text { procedure }\end{array}$ & $\begin{array}{l}\text { Follow-up } \\
\text { (months) }\end{array}$ & $\begin{array}{l}\text { Rhythm } \\
\text { during blood } \\
\text { sampling }\end{array}$ & $\begin{array}{c}\mathrm{HR} \\
(\mathrm{bpm})\end{array}$ & $\begin{array}{l}\text { LAD } \\
(\mathrm{mm})\end{array}$ & NOS \\
\hline $\begin{array}{l}\text { Nilsson, et al } \\
(2009)\end{array}$ & Retro & $51(29)$ & $32(63)$ & $55.3 \pm 10.3$ & $34(67)$ & $5.2 \pm 6.0$ & $12(24)$ & PVI & 12 & SR & NA & $39 \pm 5$ & 7 \\
\hline $\begin{array}{l}\text { Hwang, et al } \\
\text { (2009) }\end{array}$ & Pro & $73(20)$ & $64(88)$ & $53.5 \pm 10.0$ & $49(67)$ & $5.7 \pm 5.1$ & None & $\begin{array}{c}\text { PVI } \\
\text { PVI+LA }\end{array}$ & 3 & NA & NA & $42 \pm 5$ & 8 \\
\hline $\begin{array}{l}\text { Den Uijl, et al } \\
\text { (2011) }\end{array}$ & Pro & $87(21)$ & $70(80)$ & $55 \pm 9.0$ & $78(90)$ & $5.4 \pm 5.0$ & None & PVI & $6.6 \pm 3.0$ & SR & NA & NA & 8 \\
\hline $\begin{array}{l}\text { Fan, et al } \\
\text { (2012) }\end{array}$ & Pro & $33(10)$ & $23(70)$ & $56.4 \pm 10.4$ & $33(100)$ & $4.2 \pm 4.0$ & None & PVI & 3 & NA & $81.4 \pm 9.8$ & $34.2 \pm 5.6$ & 8 \\
\hline $\begin{array}{l}\text { Fiala, et al } \\
(2014)\end{array}$ & Pro & 159 (29) & $124(77)$ & $59 \pm 9.0$ & $0(0)$ & $2.3 \pm 2.4$ & None & $\begin{array}{c}\text { PVI } \\
\text { PVI+LA }\end{array}$ & 12 & $\mathrm{AF}$ & NA & $48.4 \pm 5.5$ & 8 \\
\hline $\begin{array}{l}\text { Sasaki, et al } \\
\text { (2014) }\end{array}$ & Pro & $60(29)$ & $49(82)$ & $57.6 \pm 10.9$ & $32(53)$ & $4.3 \pm 4.6$ & $8(13)$ & $\begin{array}{c}\text { PVI } \\
\text { PVI+LA }\end{array}$ & $12.1 \pm 1.0$ & NA & NA & NA & 7 \\
\hline $\begin{array}{l}\text { Giannopoulos, } \\
\text { et al (2015) }\end{array}$ & Retro & $296(93)$ & $207(70)$ & $60 \pm 8.9$ & $296(100)$ & NA & None & PVI & 13.7 & NA & NA & $43 \pm 2$ & 8 \\
\hline $\begin{array}{l}\text { Parwani, et al } \\
\text { (2015) }\end{array}$ & Pro & $87(25)$ & $57(65)$ & $62 \pm 9.0$ & $47(54)$ & NA & - $^{*}$ & $\begin{array}{c}\text { PVI } \\
\text { PVI+LA }\end{array}$ & 12 & NA & $79 \pm 23$ & $44 \pm 7$ & 8 \\
\hline
\end{tabular}

Retro indicates retrospective; Pro, prospective; AF, atrial fibrillation; SR, sinus rhythm; HF, heart failure; PVI, pulmonary vein isolation; LA, linear ablation; LAD, left atrial dimension; NOS, Newcastle-Ottawa Scale; NA, not applicable; and HR, heart rate. - ${ }^{*}$ represents heart failure patients existed but without exact number. Values are mean $\pm \mathrm{SD}$ or $n(\%)$

bias with funnel plots might not be appropriate.

Baseline BNP and post-ablation AF recurrence: Of the 10 studies on BNP included, ${ }^{4,12,15,18,19)}$ showed patients with AF recurrence after catheter ablation had significantly greater baseline BNP than those without AF recurrence. Overall, these data were synthesized with the other 6 studies $^{8,13,14,16,17,20)}$ and the pooled SMD was 0.55 (95\% CI: $0.26-0.84, P<0.001$, Figure $2)$. However, heterogeneity testing revealed a significant heterogeneity $\left(I^{2}=79 \%\right)$. To explore the potential source of heterogeneity, we performed meta-regression by covariates including AF type $(P=0.922)$, AF duration $(P=0.572)$, LAD $(P=$ $0.583)$, mean follow-up period $(P=0.380)$, and concomitant heart failure $(P=0.830)$. Since these underlying confounding factors could not explain the heterogeneity, we conducted sen- sitivity analyses but found no significant change in heterogeneity or pooled SMD when any single study was excluded.

Baseline NT-pro BNP and post-ablation AF recurrence: All 8 studies demonstrated greater baseline NT-pro BNP concentrations in the recurrence group. Quantitative data synthesis showed the overall pooled SMD was 0.96 (95\% CI: 0.62-1.30) with a $z$-test score for overall effect of $5.57(P<0.0001$, Figure $3 \mathrm{~A})$. Meta-regression was also used to explore any significant heterogeneity $\left(I^{2}=74 \%\right)$ by covariates including AF type $(P=$ $0.640)$, AF duration $(P=0.656)$, LAD $(P=0.252)$, mean follow-up period $(P=0.018)$, and concomitant heart failure $(P=$ $0.529)$. Subsequently, subgroup analysis stratified by followup period ( 3 months or $>3$ months) was conducted. The pooled SMD was 2.09 (95\% CI: 1.57-2.60, $P<0.00001)$ and 


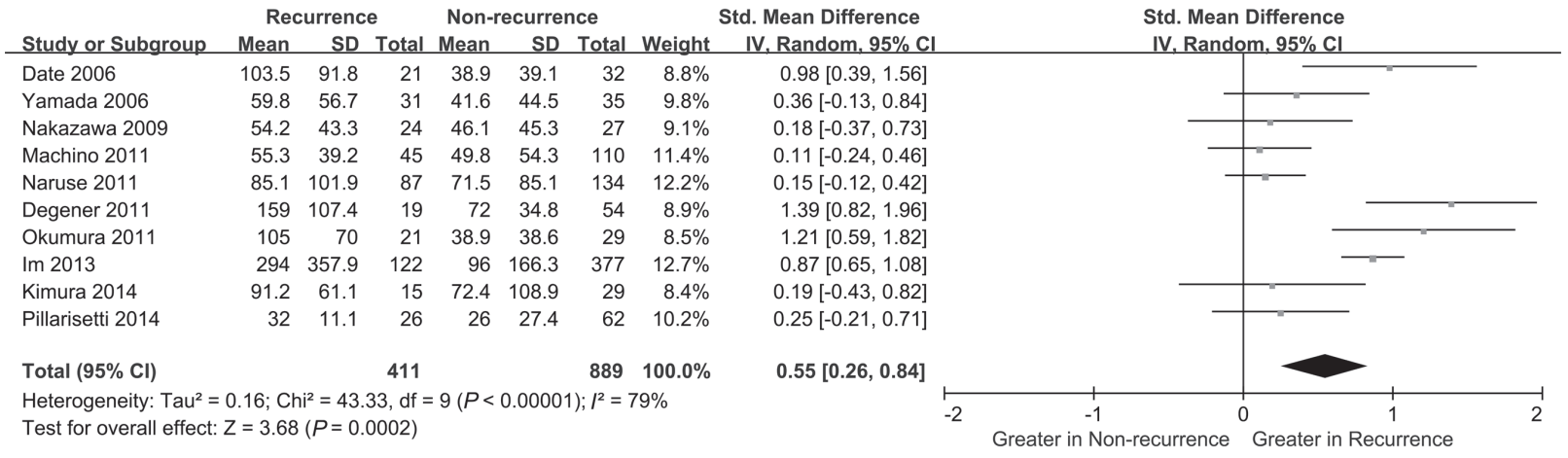

Figure 2. Forest plot of pooled SMD in studies evaluated suggested increased BNP levels and postablation AF recurrence risk.

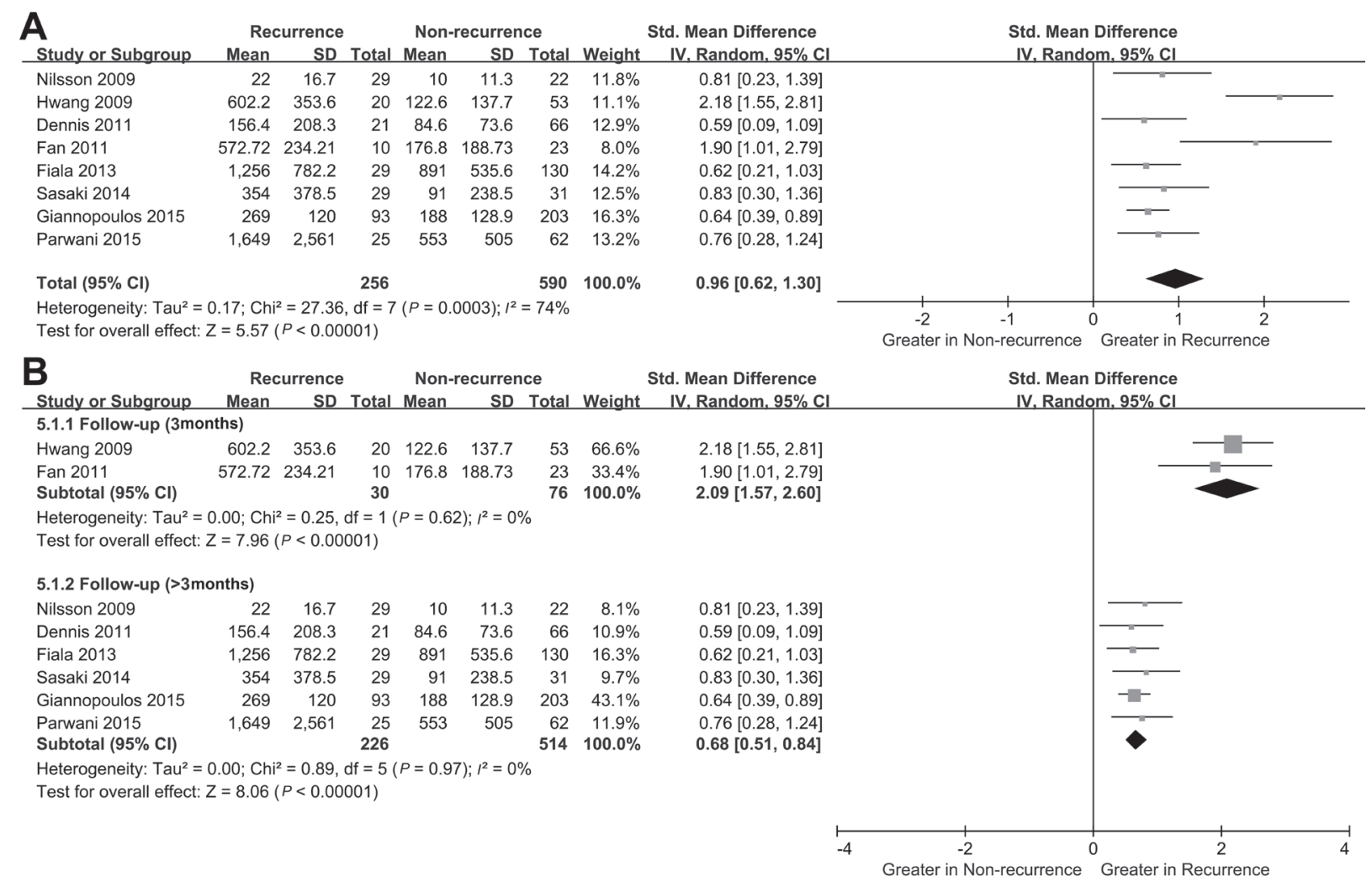

Figure 3. Forest plots of pooled SMD in studies evaluated suggested increased NT-pro BNP levels and postablation AF recurrence risk. A: Overall effect. B: Subgroup analysis by follow-up period of 3 months or $>3$ months.

0.68 (95\% CI: $0.51-0.84, P<0.00001)$ for early recurrence within 3 months and late recurrence beyond 3 months, respectively (Figure 3B). Moreover, the sensitivity analyses showed no single study significantly changed the overall pooled effects when it was excluded, demonstrating the results were stable.

\section{Discussion}

This meta-analysis identified 18 observational studies that investigated the potential association between baseline natriuretic peptides and AF recurrence after catheter ablation. The present results suggested that patients with AF recurrence have greater baseline BNP or NT-pro BNP levels, indicating a predictive role for natriuretic peptides in the recurrence of $\mathrm{AF}$ after catheter ablation.

Atrial fibrillation is a complex arrhythmia associated with increased morbidity of stroke and heart failure, as well as poor prognosis and increased mortality. ${ }^{29-31)}$ Accordingly, the current therapeutic strategies for $\mathrm{AF}$ are focused on thromboembolism prevention and rate or rhythm control. ${ }^{2)}$ Since the ectopic activities from pulmonary veins were discovered to be triggers of AF by Haissaguerre, et $a l^{32)}$ radiofrequency catheter ablation of pulmonary vein antrum has been proven to be an efficient 
treatment for rhythm control in AF patients. Furthermore, PVI and additional linear ablation or CFAE ablation have exhibited superior outcomes compared to those of antiarrhythmic drugs in rhythm control. ${ }^{33,34)}$ However, the recurrence of AF after catheter ablation is common, especially during the first 3 months, which is usually defined as early recurrence. Early recurrence tends to be transient and has also been reported as a predictor for late recurrence or long-term rhythm outcome after successful catheter ablation. ${ }^{35-37)}$ Similarly, in our metaanalysis, subgroup analysis based on follow-up period showed a higher pooled SMD $(2.09,95 \%$ CI: $1.57-2.60)$ in the early recurrence group than the pooled SMD $(0.68,95 \%$ CI: $0.51-$ 0.84 ) in the late recurrence group and the statistical heterogeneity was eliminated (Figure 3B). Thus, the follow-up period might be a potential stratification factor for further investigations, although the effect was not observed when the same subgroup analysis was conducted in currently eligible studies on BNP. Moreover, previous studies ${ }^{8,13,15,22,39)}$ have suggested that non-paroxysmal AF, longer duration of AF, and larger left atrial size might reflect higher AF burden, which is correlated with elevated natriuretic peptides levels. However, in our study, covariates including AF type, AF duration, LAD, mean followup period, and concomitant heart failure did not show significant differences on meta-regression. As a result, these factors might not be the sources of the heterogeneity in our study.

Circulating BNP and NT-pro BNP have been used as biomarkers for diagnosis, prognosis, and therapeutic monitoring in various cardiovascular diseases including heart failure, stable coronary artery disease (CAD), and acute coronary syndrome (ACS) ${ }^{4,38)}$ As for AF, elevated B-type natriuretic peptides might be strong predictors of recurrent arrhythmia after ablation, regardless of whether structural heart diseases existed. ${ }^{39)}$ This might be due to the irregular ventricular rhythm or pathophysiology of atrial substrate including hypertrophy, fibrosis, and inflammation in AF patients. Meanwhile, it should be noted that whether or how the baseline rhythm and rate status of AF patients affect the association between natriuretic peptides and post-ablation AF recurrence remain inconsistent. A study by Pillarisetti, et $a l^{8)}$ suggested that elevated BNP levels just represented atrial rhythm and ventricular rates rather than being a conclusive predictor of short-term or long-term procedural success. However, Date, et $a l^{12)}$ reported that the heart rhythm (sinus or AF) at the time of blood sampling did not affect baseline BNP concentrations and Hussein, et al ${ }^{39)}$ suggested that BNP is a strong, independent predictor of postablation AF recurrence after adjustment of cardiac or extracardiac parameters including heart rate, pre-ablation rhythm, left atrial size, age, AF duration, and the type of AF. In our meta-analysis, the studies included showed no significant differences in the baseline characteristics of age, gender, or baseline heart rate between the recurrence and non-recurrence groups. However, AF patients with concomitant heart failure were enrolled in 4 studies ${ }^{17-20)}$ on BNP and 3 studies ${ }^{21,26,28)}$ on NT-pro BNP. The meta-regression or subgroup analysis based on concomitant heart failure failed to provide a clue to the origin of heterogeneity. In addition, the study of Naruse, et $a l^{17)}$ enrolled $54(24 \%)$ patients with chronic kidney disease, while others excluded these patients or did not mention if they were excluded. Sensitivity analysis revealed this study did not eliminate the significant heterogeneity $\left(I^{2}=76 \%\right)$ and did not cause a significant change in the pooled SMD $(0.60,95 \%$ CI: 0.29 -
$0.91)$.

The concentrations of BNP and NT-pro BNP were measured by immunoradiometric assay or chemiluminescent enzyme immunoassay, with a unit of $\mathrm{pg} / \mathrm{mL}$ being used, with the exceptions of Nilsson ${ }^{21)}$ who adopted $\mathrm{pmol} / \mathrm{L}$ and Sasaki ${ }^{26)}$ who adopted $\mu \mathrm{g} / \mathrm{mL}$. Thus, the pooled SMD was applied to reflect the overall effects between studies. The general rules of thumb described by Cohen suggested that a SMD of 0.2 represents a "small" effect, a SMD of 0.5 represents a "medium" effect, and a SMD of 0.8 represents a "large" effect. ${ }^{40)}$ Accordingly, the pooled SMD of studies on BNP was 0.55 , indicating a moderate difference of baseline BNP levels between the recurrence and non-recurrence groups. For NT-pro BNP, the pooled SMD was 0.96, which represented a significant difference in baseline NT-pro BNP levels between the recurrence group and non-recurrence group. Although the studies included on NT-pro BNP showed a more consistent result and the pooled SMD of NT-pro BNP was greater than BNP, we cannot directly draw the conclusion that NT-pro BNP is a better marker than BNP. The potential advantage of NT-pro BNP is a longer half-life than BNP, which could lead to higher circulating levels and slower fluctuations. ${ }^{38)}$ A well-designed head to head comparative trial is required to determine whether NTpro BNP is more valuable than BNP or not.

Although the results indicated a significant association between increased natriuretic peptide levels and post-ablation AF recurrence, some limitations should be taken into consideration. First, since valid data for baseline rhythm and heart rate of AF patients were not applicable in most studies, this metaanalysis was conducted to identify the univariate association of baseline natriuretic peptides with post-ablation recurrence. The role of other confounding clinical factors should be estimated in the future. Second, all studies included were observational studies rather than randomized control trials (RCT), some of which had a relatively small sample size $(<100)$. Third, significant heterogeneity existed in the quantitative syntheses with the random effect model that was used. As the results of the meta-regression and subgroup analyses showed above, it might be partially due to differences in the complicated clinical characteristics of the enrolled patients between studies. Fourth, the association between post-ablation $\mathrm{AF}$ recurrence risk and baseline natriuretic peptides was indicated by the pooled SMD indirectly. The SMD mainly expressed the size of the difference in natriuretic peptide levels in each study relative to the variability observed in that study. If further studies were available, the statistical power of the pooled risk ratio or odds ratio would be greater than SMD. Finally, publication bias cannot be completely excluded in this study as only a small number of studies were included. Meanwhile, effect estimates like SMD that are naturally correlated with standard errors can produce spurious asymmetry in a funnel plot.

Conclusion: Our meta-analysis indicated that increased baseline natriuretic peptides, both BNP and NT-pro BNP, are associated with greater risk of $\mathrm{AF}$ recurrence after catheter ablation. Considering the limitations described above, further well designed, larger, and long-term studies in specific populations are needed to elucidate the predictive value of baseline natriuretic peptides in $\mathrm{AF}$ patients undergoing catheter ablation. 


\section{DisClOSURES}

The authors have no conflicts of interest to disclose.

\section{REFERENCES}

1. Chugh SS, Havmoeller R, Narayanan K, et al. Worldwide epidemiology of atrial fibrillation: a Global Burden of Disease 2010 Study. Circulation 2014; 129: 837-47.

2. January CT, Wann LS, Alpert JS, et al. 2014 AHA/ACC/HRS guideline for the management of patients with atrial fibrillation: a report of the American College of Cardiology/American Heart Association Task Force on practice guidelines and the Heart Rhythm Society. Circulation 2014; 130: 2071-104.

3. Haegeli LM, Calkins H. Catheter ablation of atrial fibrillation: an update. Eur Heart J 2014; 35: 2454-9. (Review)

4. Volpe M, Rubattu S, Burnett J Jr. Natriuretic peptides in cardiovascular diseases: current use and perspectives. Eur Heart J 2014 35: 419-25. (Review)

5. Wozakowska-Kaplon B. Effect of sinus rhythm restoration on plasma brain natriuretic peptide in patients with atrial fibrillation. Am J Cardiol 2004; 93: 1555-8.

6. Knudsen CW, Omland T, Clopton P, et al. Impact of atrial fibrillation on the diagnostic performance of B-type natriuretic peptide concentration in dyspneic patients: an analysis from the breathing not properly multinational study. J Am Coll Cardiol 2005; 46: 838-44.

7. Ellinor PT, Low AF, Patton KK, Shea MA, Macrae CA. Discordant atrial natriuretic peptide and brain natriuretic peptide levels in lone atrial fibrillation. J Am Coll Cardiol 2005; 45: 82-6.

8. Pillarisetti J, Reddy N, Biria M, et al. Elevated brain natriuretic peptide level in patients undergoing atrial fibrillation ablation: is it a predictor of failed ablation or a mere function of atrial rhythm and rate at a point in time? J Interv Card Electrophysiol 2014; 40: 161-8.

9. Stroup DF, Berlin JA, Morton SC, et al. Meta-analysis of observational studies in epidemiology: a proposal for reporting. Metaanalysis Of Observational Studies in Epidemiology (MOOSE) group. JAMA 2000; 283: 2008-12. (Review)

10. Higgins J, Green S, eds. Cochrane Handbook for Systematic Reviews of Interventions Version 5.1.0 [updated March 2011]. The Cochrane Collaboration, 2011. Available at: http://www.cochranehandbook.org. Accessed August 16, 2015.

11. Ottawa Hospital Research Institute. The Newcastle-Ottawa Scale (NOS) for assessing the quality of nonrandomized studies in metaanalyses. Available at: http://www.ohri.ca/programs/clinical_ epidemiology/nosgen.pdf. Accessed August 16, 2015.

12. Date T, Yamane T, Inada K, et al. Plasma brain natriuretic peptide concentrations in patients undergoing pulmonary vein isolation. Heart 2006; 92: 1623-7.

13. Yamada T, Murakami Y, Okada T, et al. Plasma atrial natriuretic Peptide and brain natriuretic Peptide levels after radiofrequency catheter ablation of atrial fibrillation. Am J Cardiol 2006; 97 : 1741-4.

14. Nakazawa Y, Ashihara T, Tsutamoto T, Ito M, Horie M. Endothelin-1 as a predictor of atrial fibrillation recurrence after pulmonary vein isolation. Heart Rhythm 2009; 6: 725-30.

15. Degener S, Pattberg SV, Feuersenger H, et al. Predictive value of B-type natriuretic peptide levels in patients with paroxysmal and persistent atrial fibrillation undergoing pulmonary vein isolation. J Interv Card Electrophysiol 2011; 30: 217-25.

16. Machino-Ohtsuka T, Seo Y, Tada H, et al. Left atrial stiffness relates to left ventricular diastolic dysfunction and recurrence after pulmonary vein isolation for atrial fibrillation. J Cardiovasc Electrophysiol 2011; 22: 999-1006.

17. Naruse $\mathrm{Y}$, Tada H, Sekiguchi $\mathrm{Y}$, et al. Concomitant chronic kidney disease increases the recurrence of atrial fibrillation after catheter ablation of atrial fibrillation: a mid-term follow-up. Heart Rhythm
2011; 8: 335-41.

18. Okumura Y, Watanabe I, Nakai T, et al. Impact of biomarkers of inflammation and extracellular matrix turnover on the outcome of atrial fibrillation ablation: importance of matrix metalloproteinase-2 as a predictor of atrial fibrillation recurrence. J Cardiovasc Electrophysiol 2011; 22: 987-93.

19. Im SI, Shin SY, Na JO, et al. Usefulness of neutrophil/lymphocyte ratio in predicting early recurrence after radiofrequency catheter ablation in patients with atrial fibrillation. Int J Cardiol 2013; 168 : 4398-400.

20. Kimura $\mathrm{T}$, Takatsuki $\mathrm{S}$, Inagawa $\mathrm{K}$, et al. Serum inflammation markers predicting successful initial catheter ablation for atrial fibrillation. Heart Lung Circ 2014; 23: 636-43.

21. Nilsson B, Goetze JP, Chen X, Pehrson S, Svendsen JH. Increased NT-pro-B-type natriuretic peptide independently predicts outcome following catheter ablation of atrial fibrillation. Scand J Clin Lab Invest 2009; 69: 843-50.

22. Hwang HJ, Son JW, Nam BH, et al. Incremental predictive value of pre-procedural $\mathrm{N}$-terminal pro-B-type natriuretic peptide for short-term recurrence in atrial fibrillation ablation. Clin Res Cardiol 2009; 98: 213-8.

23. den Uijl DW, Delgado V, Tops LF, et al. Natriuretic peptide levels predict recurrence of atrial fibrillation after radiofrequency catheter ablation. Am Heart J 2011; 161: 197-203.

24. Fan J, Cao H, Su L, et al. NT-proBNP, but not ANP and C-reactive protein, is predictive of paroxysmal atrial fibrillation in patients undergoing pulmonary vein isolation. J Interv Card Electrophysiol 2012; 33: 93-100.

25. Fiala $\mathrm{M}$, Wichterle $\mathrm{D}$, Bulková $\mathrm{V}$, et al. A prospective evaluation of haemodynamics, functional status, and quality of life after radiofrequency catheter ablation of long-standing persistent atrial fibrillation. Europace 2014; 16: 15-25.

26. Sasaki N, Okumura Y, Watanabe I, et al. Increased levels of inflammatory and extracellular matrix turnover biomarkers persist despite reverse atrial structural remodeling during the first year after atrial fibrillation ablation. J Interv Card Electrophysiol 2014; 39: 241-9.

27. Giannopoulos G, Kossyvakis C, Angelidis C, et al. Amino-terminal B-natriuretic peptide levels and postablation recurrence in hypertensive patients with paroxysmal atrial fibrillation. Heart Rhythm 2015; 12: 1470-5.

28. Parwani AS, von Haehling S, Kolodziejski AI, et al. Mid-regional proadrenomedullin levels predict recurrence of atrial fibrillation after catheter ablation. Int J Cardiol 2015; 180: 129-33.

29. Kannel WB, Wolf PA, Benjamin EJ, Levy D. Prevalence, incidence, prognosis, and predisposing conditions for atrial fibrillation: population-based estimates. Am J Cardiol 1998; 82: 2N-9N.

30. Benjamin EJ, Wolf PA, D'Agostino RB, Silbershatz H, Kannel WB, Levy D. Impact of atrial fibrillation on the risk of death: the Framingham Heart Study. Circulation 1998; 98: 946-52.

31. Wang TJ, Larson MG, Levy D, et al. Temporal relations of atrial fibrillation and congestive heart failure and their joint influence on mortality: the Framingham Heart Study. Circulation 2003; 107: 2920-5.

32. Haissaguerre M, Jaïs $\mathrm{P}$, Shah DC, et al. Spontaneous initiation of atrial fibrillation by ectopic beats originating in the pulmonary veins. N Engl J Med 1998; 339: 659-66.

33. Noheria A, Kumar A, Wylie JV Jr, Josephson ME. Catheter ablation vs antiarrhythmic drug therapy for atrial fibrillation: a systematic review. Arch Intern Med 2008; 168: 581-6. (Review)

34. Calkins H, Reynolds MR, Spector P, et al. Treatment of atrial fibrillation with antiarrhythmic drugs or radiofrequency ablation: two systematic literature reviews and meta-analyses. Circ Arrhythm Electrophysiol 2009; 2: 349-61. (Review)

35. Cai L, Yin Y, Ling Z, et al. Predictors of late recurrence of atrial fibrillation after catheter ablation. Int J Cardiol 2013; 164: 82-7.

36. Evranos B, Aytemir K, Oto A, et al. Predictors of atrial fibrillation recurrence after atrial fibrillation ablation with cryoballoon. Cardiol J 2013; 20: 294-303.

37. Mulder AA, Wijffels MC, Wever EF, Boersma LV. Early recur- 
rence of atrial fibrillation as a predictor for 1-year efficacy after successful phased RF pulmonary vein isolation: evaluation of complaints and multiple Holter recordings. Int J Cardiol 2013; 165: 56-60.

38. Daniels LB, Maisel AS. Natriuretic peptides. J Am Coll Cardiol 2007; 50: 2357-68. (Review)

39. Hussein AA, Saliba WI, Martin DO, et al. Plasma B-type natriu- retic peptide levels and recurrent arrhythmia after successful ablation of lone atrial fibrillation. Circulation 2011; 123: 2077-82.

40. Takeshima N, Sozu T, Tajika A, Ogawa Y, Hayasaka Y, Furukawa TA. Which is more generalizable, powerful and interpretable in meta-analyses, mean difference or standardized mean difference? BMC Med Res Methodol 2014; 14: 30. 